\title{
SHAM: High-Level Seismic Tests of Piping at the HDR
}

by

C. A. Kot, M. G. Srinivasan, B. J. Hsieh, Argonne National Laboratory; DE,89 104285

L. Malcher, D. Schrammel, Kernforschungszentrum, Karisruhe, FRG;

H. Steinhilber, Fraunhofer Institut für Betriebsfestigkeit, Darmstadt, FRG;

J. F. Costello, U. S. Nuclear Regulatory Commission, Office of Research

\section{ABSTRACT}

As part of the second phase of vibraticnal/earthquake investigations at the HDR (Heissdampfreaktor) Test Facility in Kahl/Main, FRG, high-level simulated seismic tests (SHAM) were pertormed during April-May 1988 on the VKL (Versuchskreislauf) in-plant piping system with two servohydraulic actuators, each capable of generating 40 tons of forcs. The purpose of these experiments was to study the behavior of piping subjected to seismic excitation levels that exceed design levels manifold and may result in failure/plastification of pipe supports and pipe elements, and to establish seismic margins for piping and pipe supports. The performance of six different dynamic pipe support systems was compared in these tests and the response, operability, and fragility of dynamic supports and of a typical $U$. S. gate valve were investigated. Data obtained in the tests are used to validate analysis methods. Very preliminary evaluations lead to the observation that, in general, failures of dynamic supports (in particular snubbers) occur only at load levels that substantially exceed the design capacity. Pipe strains at load levels exceeding the design level threefold aie quite small, and even when exceeding the design level eightfoid are quite tolerable. Hence, under seismic loading, even at extreme levels and in spite of multiple support failures, pipe failure is unlikely.

\section{Introduction}

The Heissdampireaktor (HDR) Test Facility in Kahi/Main, Federal Republic of Germany (FRG), ras been used since 1974 by the HDR Safety Project (PHDR) of the Kernforschungszentrum Karlsruhe (KiK), FRG, to perform vibrational, thermal hydraulic, blowdown, and ciher experiments related to the design and safety of nuclear power plants. As part of the current second-phase testing, high-level seismic experiments, designated SHAM, were performed on an in-plant piping system during the period of 19 April to 27 May 1988. These experiments were intended as a companion test series to the SHAG tests performed in 1986 [1,2], in which the reactor containment building was tested to incipient failure. Thus, the objectives of the S: HAM experiments were to (i) study the response of piping subjected to seismic excitation levels that exceed design levels manifold and which may result in failure/plastification of pipe supports and pipe elements; (ii) provide data for the validation of linear and nonlinear pipe response analyses; (iii) compare and evaluate, under identical loading conditions, the performance of various dynamic support systems, ranging from very flexible to very stiff support configurations; (iv) establish seismic margins for piping, dynamic pipe supports, and pipe anchorages; and (v) investigate the response, operability, and fragility of dynamic supports and of a typical U.S. gate valve under extreme levels of seismic excitation.

The SHAM experiments were conducted as a cooperative effort among a rumber of organizations in Europe and the USA. These included KfK/PHL)R, with the participation of the Fraunhofer Institut für Betriebsfestigkeit (LBF), Darmstadt, FRG, and the Kraftwerk Union (KWU), Offenbach, FnG; the Central Electricity Generating Board (CEGB), Lik; the Eiectric Power Hesearch Institute (EPRI), Palo Alto, California, with the participation of Bechtel Corp. and A. C. Cloud \& Associates; and the U.S. Nuclear Regulatory Commission, Office of Research (NRC/RES), which supported the efforts of Argonne National Laboratory (ANL) and Idaho National Engineering Laboratory (INEL).

$$
\text { MASTER }
$$

The sutbmited manuserpt has been duthored by a contiator of the U.S jovernment under rontract No. W31 109ENG 38. Accilldingly, the US Government tetarns a nomenclusive. rovaliy liet: license to publish reproduce the published form of this contribution, or allow urhers to du so, for $U S$ Government purposes 
A brief description of the SHAM tests is provided, including the design of the experiments and hardware, the test procedures and approach, and the instrumentation and data acquisition. Since the experimental data are just now becoming available, only highlights of the test results are given primarily in the form of maximum response values. Also presented are very limited comparisons of experimental data and pretest analytical predictions. All results and conclusions presented here should be considered preliminary.

\section{Description of the SHAM Experiments}

The test object in the SHAM experimerts was the VKL (Versuchsk:eislauf) piping system thai was already extensively tested in the SHAG experiments $[1,2]$. In the lattar tests, excitation of the piping resulted Irom the shaking of the HDR containment building. In the SH. shaking of the VKL piping was used. Therefore, some significant modification of the test loop was necessary.

\subsection{Test Design and Set-up}

An isometric sketch of the VKL piping as used in the SHAM testing is shown in Figure 1. The VKL piping is located between the 18-and 24-m elevations in the HDR facility, and it consists of multiple stainless steel pipe branches ranging from 100 to $300 \mathrm{~mm}$ in diameter, with the main two flow loops connected to the HDU vessel and the DF16 manifold. A third major branch connects the DF16 manifold to the DF15 manifold. Aside from the pipe hangers and dynamic supporis, the only points of fixity for the entire system, including the HDU and manifolds, are the supports at the bottom of the HDU and the nearly rigid attachment of the DF15 manifold. All extraneous piping leading to other flow systems in the HDR were disconnected for the SHAM tests. As in the earlier tests, the test loop again included an 8" U.S. gate valve from the decommissioned Shippingport Atomic Power Station. This valve was returbished prior to testing at the HDR, and its motor operator was equipped with a new AC motor, torque switch, and torque spring prior to the SHAM testing.

The VKL piping was excited directly by means of two servohydraulic actuators rated at 40 tons (metric) of force each. As shown in Fig. 1, both act?:ators were acting in the horizontal $x$-direction at hanger location $\mathrm{H} 5$ and at location $\mathrm{H} 25$ (DF16 manifold). The excitation system was designed and furnished by LBF-Darmstadt, FRG, and included a computer-controlled hydraulic actuating/control system to provide predetermined displacement-time histories. Extensive pretest design caiculations indicated that the hydraulic shakers shouid be capable of producing up to $6 \mathrm{~g}$ acceleration for the VKLL piping, with a maximum displacement (stroke) of $\pm 125 \mathrm{~mm}$ [3].

Six different dynamic support systems of the VKL piping were designed by the various participants in the SHAM testing. These ranged from the very stiff U.S. system with rigid struts and snubbers to a very flexible HDR system with essentially only dead-weight supports. Two support configurations, provided by EFRI in collaboration with indusinal partners, contained snubber replacement devices. The first of these, designed by Bechtel Power Corp., uses Energy Absorber (EA) clevices, in which a set of specially designed steel plates is plastically deformed to dissipate energy and restrict pipe motion under seismic loading. The second snubber replacement system, designed by R. L. Cloud \& Associates, Inc., includes Seismic Stops (SS). In their current design, these stops are simple telescoping-lube devices with preset internal gaps that allow a certain amount of motion to accommodate thermal effects. During seismic excitation, the motion is restricted/stopped by impacting on dise spring pads. Two other support configurations, designed by KWU and CEGB, rely only on rigid struts for dynamic restraint. Figure 2 shows an overview of all the support configurations with the location and type of dynamic support clearly indicated. All configurations used the same dead-weight hariger system shown in Fig. 1. Similarly, all configuraticns employed the same rigid struts at locations $\mathrm{H} 4$ and H23. These are horizontal struts in the $z$-direction and their primary function is to stabilize the input motions of the actuators, at H5 and DF16 respectively, so that they move only in the $x$-direction. The components of these supports were sized for the highest loads anticipated. 


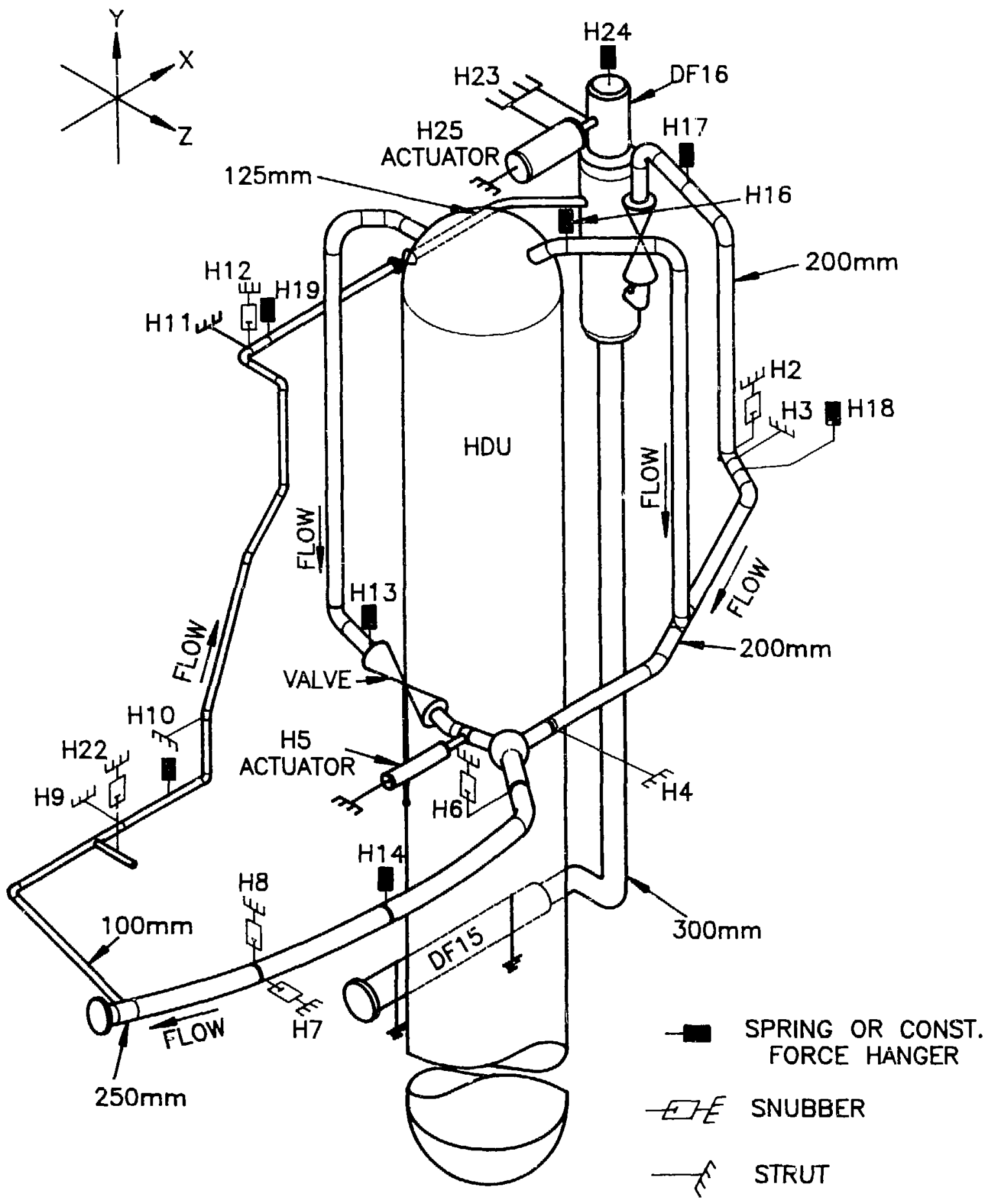

Fig. 1. SHAM Test Configuration - VKL Piping with US NRC Supports 


\begin{tabular}{|c|c|c|c|c|c|c|}
\hline $\begin{array}{l}\text { Hang- } \\
\text { er No. }\end{array}$ & HDR & $\mathrm{kWW}^{2}$ & ${ }^{3}$ & $\begin{array}{c}4 \\
\text { EPRI/EA }\end{array}$ & $\begin{array}{c}5 \\
\text { EPRI/SS }\end{array}$ & CEGB \\
\hline 2 & & 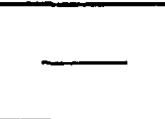 & $\begin{array}{c}\text { Snubber } \\
\text { PSA: }\end{array}$ & - & $\begin{array}{c}\text { Seismic } \\
\text { stop }\end{array}$ & L \\
\hline 3 & & - & \multicolumn{3}{|c|}{$\begin{array}{l}\text { Strut } \\
\text { Size B } \\
\end{array}$} & 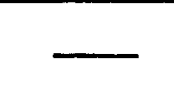 \\
\hline 4 & \multicolumn{6}{|c|}{$\begin{array}{l}\text { Strut } \\
\text { Size } 20\end{array}$} \\
\hline 6 & & - & $\begin{array}{l}\text { Snubber } \\
\text { PSA } 1 / 2 \\
\end{array}$ & $\longrightarrow$ & $\begin{array}{c}\text { Seismic } \\
\text { stop }\end{array}$ & - \\
\hline 7 & & & \begin{tabular}{|l|} 
Snubber \\
A/D 150 \\
\end{tabular} & $\begin{array}{c}\text { Energy } \\
\text { Absorber }\end{array}$ & $\begin{array}{l}\text { Seismic } \\
\text { stop }\end{array}$ & $\begin{array}{l}\text { Strut } \\
\text { RS-15 } \\
\end{array}$ \\
\hline 8 & & 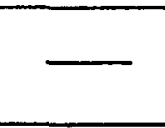 & $\begin{array}{l}\text { Snubber } \\
\text { A/D } 70 \\
\end{array}$ & $\begin{array}{c}\text { Energy } \\
\text { Absorber }\end{array}$ & $\begin{array}{c}\text { Seismic } \\
\text { stop }\end{array}$ & $\begin{array}{l}\text { Strut } \\
\text { RS-7 } \\
\end{array}$ \\
\hline 9 & & $\begin{array}{l}\text { Strut } \\
\text { Size B }\end{array}$ & \multicolumn{3}{|c|}{$\begin{array}{l}\text { Strut } \\
\text { Size A } \\
\end{array}$} & $\begin{array}{l}\text { Strut } \\
\text { RS-7 }\end{array}$ \\
\hline 10 & 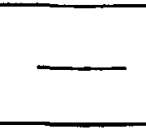 & $\begin{array}{l}\text { Strut } \\
\text { Size B } \\
\end{array}$ & \multicolumn{3}{|c|}{$\begin{array}{l}\text { Strut } \\
\text { Size A } \\
\end{array}$} & \\
\hline 11 & & $\begin{array}{r}\text { Strut } \\
\text { Size B } \\
\end{array}$ & \multicolumn{3}{|c|}{$\begin{array}{l}\text { Strut } \\
\text { Size A } \\
\end{array}$} & 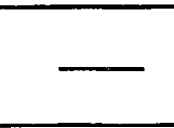 \\
\hline 12 & & - & $\begin{array}{l}\text { Snubber } \\
\text { AD } 40 \\
\end{array}$ & 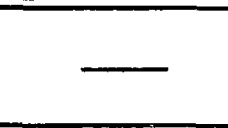 & $\begin{array}{c}\text { Seismic } \\
\text { stop }\end{array}$ & $\begin{array}{r}\text { Strut } \\
\text { RS-15 } \\
\end{array}$ \\
\hline 22 & - & $\longrightarrow$ & $\begin{array}{l}\text { Snubber } \\
\text { PSA 1/4 } \\
\end{array}$ & $\begin{array}{c}\text { Energy } \\
\text { Absorber }\end{array}$ & $\begin{array}{c}\text { Seismic } \\
\text { stop }\end{array}$ & - \\
\hline 23 & & & $\begin{array}{l}\text { TwO } \\
2 \times S\end{array}$ & $\begin{array}{l}\text { Struts } \\
\text { ze } 20 \\
\end{array}$ & & \\
\hline
\end{tabular}

Fig. 2. Dynamic Support Configurations for VKL Piping used in SHAM Tests 
All dynamic support systems except that designed by CEGB were designed for the common HDR spectrum shown in Fig. 3. The actuators were displacement controlled, and the basic earthquak: displacement history Lsed was an artificially generated displacement-time function of 15 seconds duration (see Fig. 4), fitted to the preselected common Safe Shutdown Earthquake (SSE)-floorresponse spectrum with a $0.6 \mathrm{~g}$ peak acceleration $(Z P A)$, shown in Fig. 3 . The supports for the U.S. stiff support system were designed by INEL with typical U.S. struts from Grinnell and snubbers from Pacific Scientific (PSA) and Anchor Darling Industries (AD). INEL analyzed the VKL piping system for seismic response using a typical nuclear plant design approach and basing their allowables on the 1979 ASME Code. To permit the evaluation of seismic margins and failure modes of support components at reasonably low levels of earthquake excitation, the dy'namic supports were sized for Level "C" allowables for the expected SSE loading. While the other support configurations, i.e., KWU, EPRI/EA, and EPRI/SS, were also designed for the same floor-response-spectrum arid a ZPA of $0.6 \mathrm{~g}$, they were sized for more conservative allowables. The HDR flexible support system was essentially not designed for seismic lcading and only contained the rigid struts required to stabilize the hydraulic actuators $(\mathrm{H} 4, \mathrm{H} 23)$. Finally, the CEGB hanger system was designed for the Sizewell B spectrum shown in Fig. 3 and was tested with displacement histories of $20-5$ duration, corresponding to that specirum and the Allsites spectrum shown in Fig. 3.

To study the behavior and fragility of typical pipe mountings and anchorages, trunions were installed at locations $\mathrm{H}_{2}$ and $\mathrm{H}_{2} 2$ (see Fig. 1). At the same time, the anchor plates and anchors at these locations were replaced with typical U.S. harciware, sized for the design spectrum and SSE level.

\subsection{Instrumentation ane Data Acquisition}

Nearly 300 channels of data were recorded, with major measurements being strains (142 channels), accelerations (90 channels), displacements (29 channels), and forces (27 channels). In addition, 10 channels were used to monitor the operating parameters of the U.S. 8" gate valve. All important aspects of the experiments were monitored; this included the excitation systems (actuators) where displacements, accelerations, and forces were measured. The pipe responses (accelerations) at the driving points were also measured. Displacement and forces of dynamic supports were recorded, as were the pipe accelerations at the point of support attachment. Additional accelerations and displacements were recorded at points where large responses were expected. Finally, strain measurements were made throughout the piping system. Again, pipe locations and elbows where the strain was expected to be high were selected. In particular, the first pipe elbow (Elbow 1) adjacent to the DF16 manifold (see Fig. 1) was monitored, as was the 100-mm pipe next to the reduction tee, and the elbow following that tee (Elbow 2). Stress coating, applied at some locations of the pipe, was monitored during the testing to provide early indication of severe straining. Details of the instrumentation can be found in the Test Design Report [3] and the Test Protocol [4].

During conversion to digital form the data were originally acquired at a rate of $625 \mathrm{~Hz}$ and filtered at $100 \mathrm{~Hz}$. Before final storage in the computer of the HDR Central Measurement Facility (ZMA), the data acquisition rate was redured by a factor of three; i.e., to $208.3 \mathrm{~Hz}$; and the data were digitally low-pass filtered at $60 \mathrm{~Hz}$. After plausibility checks and offset corrections, the data are now made available in this form to the users by the Central Evaluation Computer (ZAW) of KfKJPHDR.

\subsection{Experlinents Performed}

Fifty-one individual experiments were performed with the VKL piping and the six different pipe suppori configurations. Two random excitation tests of i20-s duration, with each of the hydraulic actuators singly and separately (H5 and DF16) were performed for each hanger configuration. These tests provides dynamic characterization of the systems in the frequency range from 2 to $40 \mathrm{~Hz}$. The maximum excitation level in these tests was approximately $0.3 \mathrm{~g}$ with a maximum actuator piston displacement of around $\pm 3 \mathrm{~mm}$. 


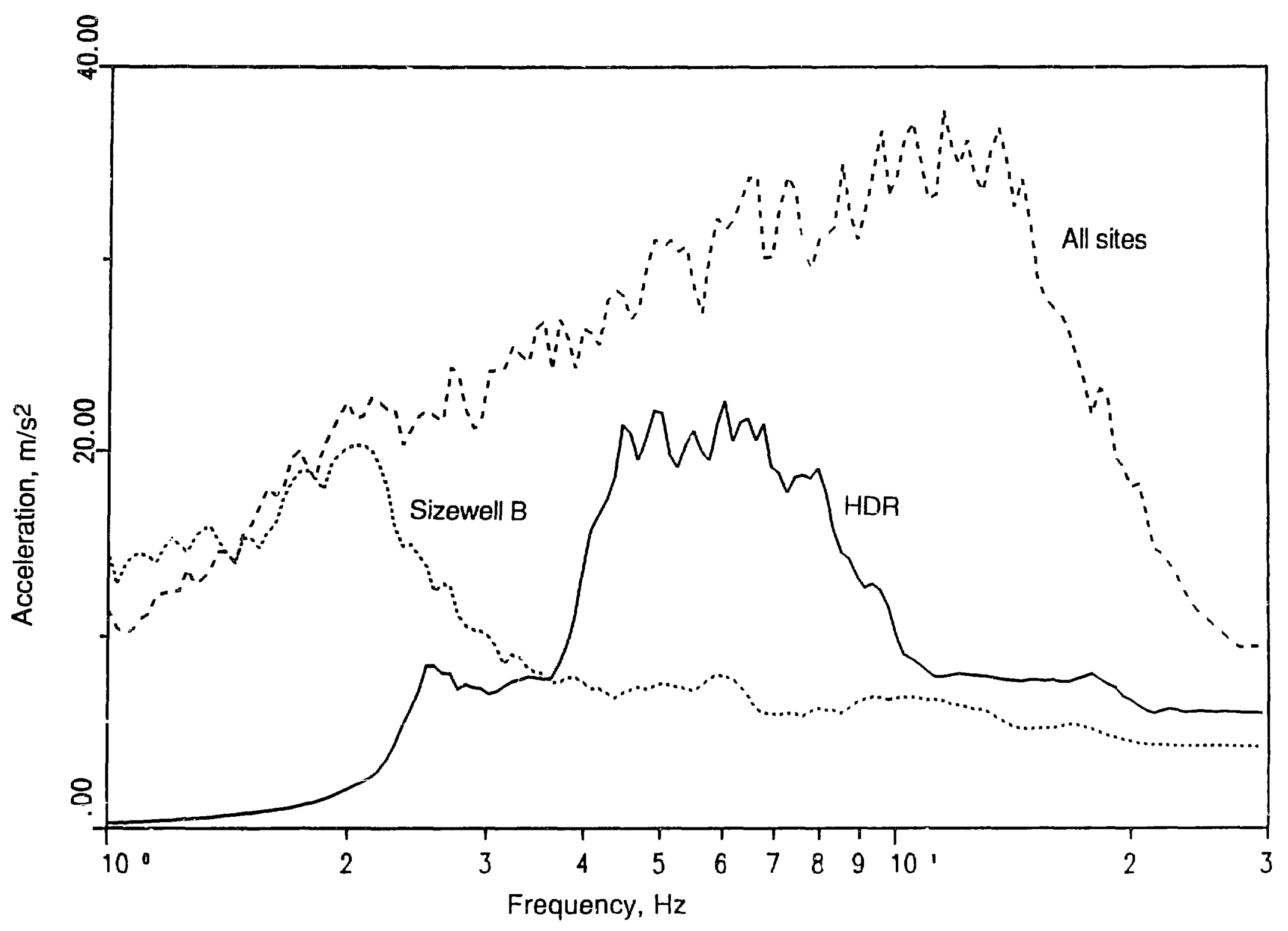

Fig. 3. Spectra of the Earthquake Excitations, 100\%-SSE, 4\% Damping 


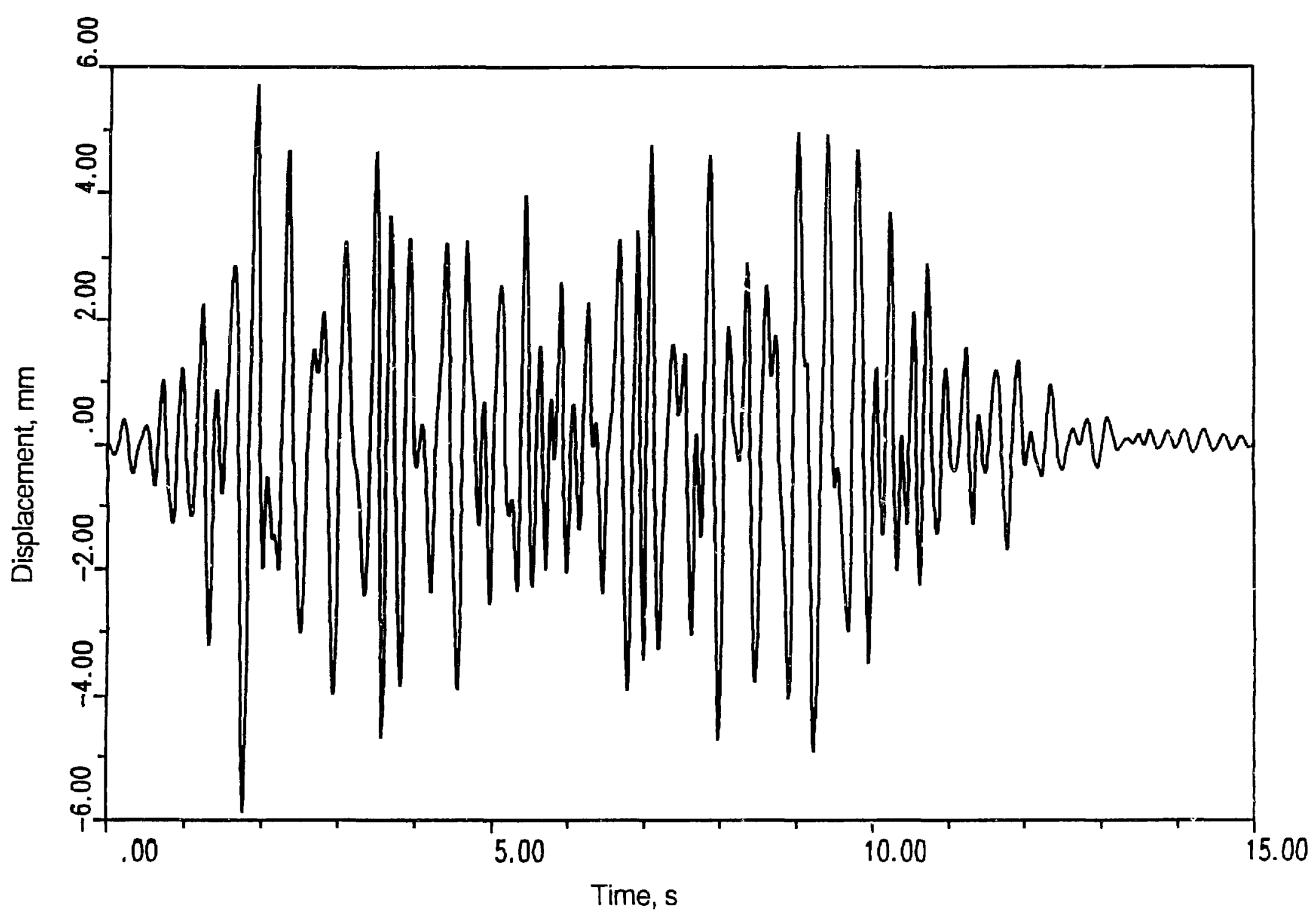

Fig. 4. Earthquake Displacement-Time History for the HDR 100\%-SSE Spectrum 
For all but the CEGB configuration, earthquake experiments were then performed at the low to iniermediate level, i.e., at excitation levels ranging from one SSE $(0.6 \mathrm{~g} \mathrm{ZPA})$ to three (four) SSE. These experiments were carried out with the 15-s duration displacement history based on the common HDR spectrum (see Fig. 4) scaled to the proper SSE level. The two hydraulic actuators (at H5 and DF16) were operated together and in phase; both were programmed to provide identical displacement historios. The purpose of these tests was to study the behavior of piping systems at load levels exceeding the design load ano to compare the performance of different support configurations. To make these tests possible with all configurations, strains in the piping were required to remain below significant plastification, i.e., about $0.2 \%$ of strain. These tests were also intended to provide seismic-margin information lor dynamic supports, and data for the validation of linear analyses.

Two configurations, namely the KWU system and a modified NRC system, were then tested to high levels of excitation (Up to $800 \%$ SSE) aģain with scaled-up displacement histories and both actuators operating in phase. The modification of the NAC system consisted of providing a stiff bridging (welded box beam) between the DF16 manifold and the $200 \mathrm{~mm}$ J-pipe extending from it. This bridging was intended to prevent excessive straining of the first elbow adjacent to the DF16 manifold and to provide a more uniform load distribution throughout the piping system. The elbow in question exhibited the highest strains in the lower level tests and any eventual failure at this elbow would not be considered prototypical of real earthquake loading but rather as "engineered" by the hydraulic actuator excitation. The purpose of the high-level tests was to obtain information on possible pipe failure/plastification, seismic margins for piping, and pipe supports, and to provide data for the validation of nonlinear analysis methods.

The CEGB configuration was subjected to its own test program. Low- and intermediate-level earthquake tests were performed with displacement histories of 20-s duration derived from the Sizewell B and Allsites spectra (see Fig. 3). Intermediate- and high-level tests were also performed with sine burst histories. Finally, to provide a companison with the other configurations, a 100\% SSE earthquake test was performed with the displacement history derived from the common HDR spectrum.

\section{SHAM Results}

As indicated earlier, analysis of the very large volume of SHAM test data is just beginning. The following preliminary overview of the results is based primarily on the exposition of maximum responses for selected variables in the experiments. In order to obtain consistent and comparable results in the earthquake testing of all the support configurations that were subjected to the common HDR spectrum, it was our intention to control the input acceleration spectra for the two actuators within a tolerance of $\pm 10 \%$ in amplitude. Figures 5 and 6 provide the actual measured input spectra for the experiments at $100 \%$ and $300 \%$, SSE, rESpectively. Also shown in these figures are the desired tolerance bounds for the spectra. It can be seen that at $100 \%$ SSE, up to frequencies of about $10 \mathrm{H}_{2}$, the experimental spectra generally meet the stipulated requirements, with the actuator at DF16 producing less scatter than the one at H5. At higher frequencies, the tolerance criterion is not satisfied very well, and peaking of the spectra generally occurs between 15 and $20 \mathrm{~Hz}$. The magnitude of this peak varies from configuration to configuration. At this time, it is not clear if this is indeed an input characteristic, or if the strong deviation from the desired spectra represents feedback from the piping system. Please note that displacement, and not acceleration, was the controlled variable. This point requires further investigation. In the $300 \%-$ SSE experiments, at the H5 actuator of the stiff U.S. NRC configuration, strong deviations from the desired spectrum can be seen even in the lower frequency range, with the peak amplitude overshoot being nearly twice as high as the intended value. Similar discrepancies have also been found for the $200 \%-S S E$ experiments. At higher levels of excitation $(400,600$, and $800 \%$ SSE), the input spectra are similar to those at $100 \%$ SSE.

The large deviations from the expected spectra and the differences between various configurations make comparisons somewhat problematic. Approaches to overcome this problem must be 

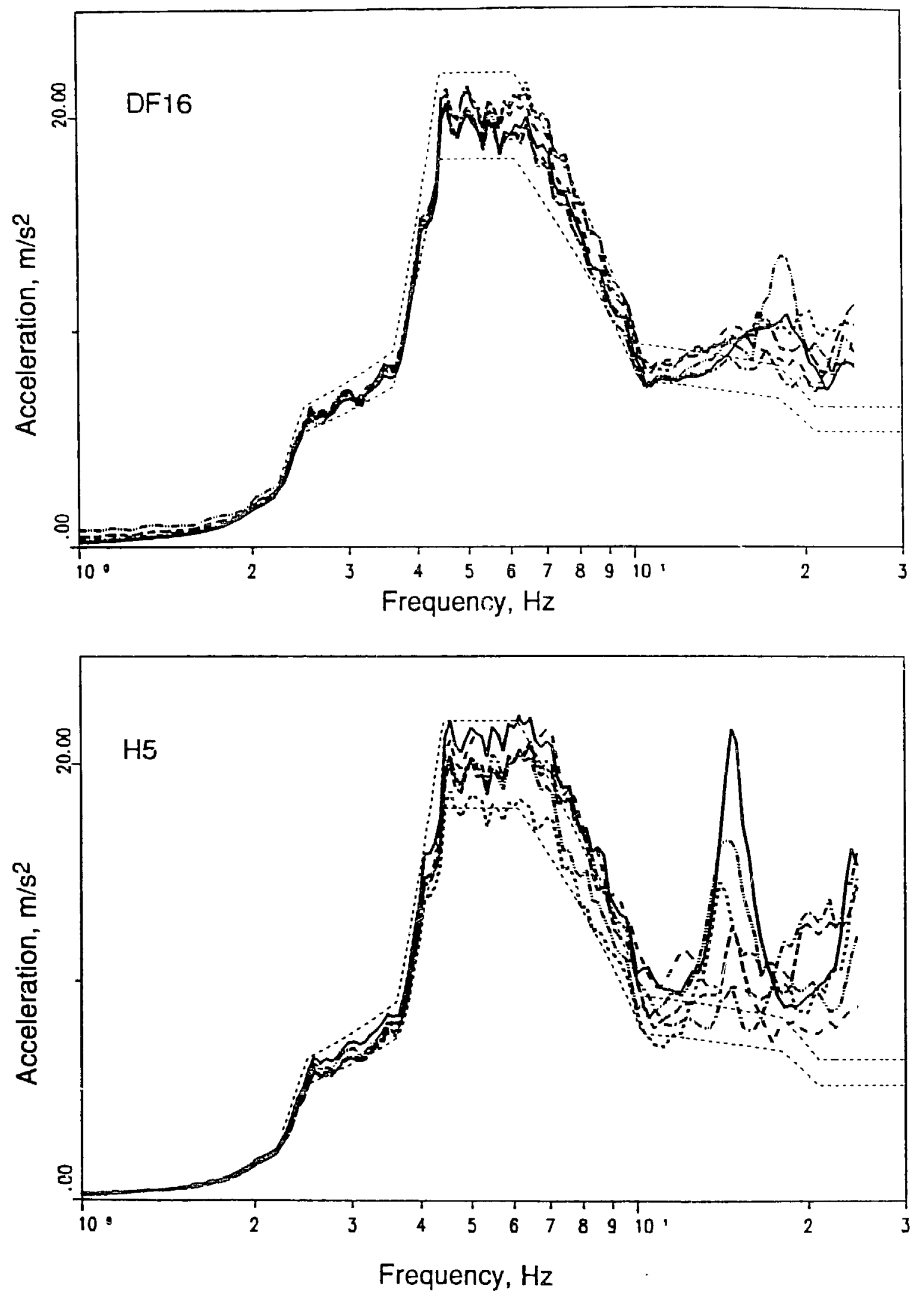

Fig. 5. Input Response Spectra for $100 \%$-SSE Experiments, 4\% Damping 

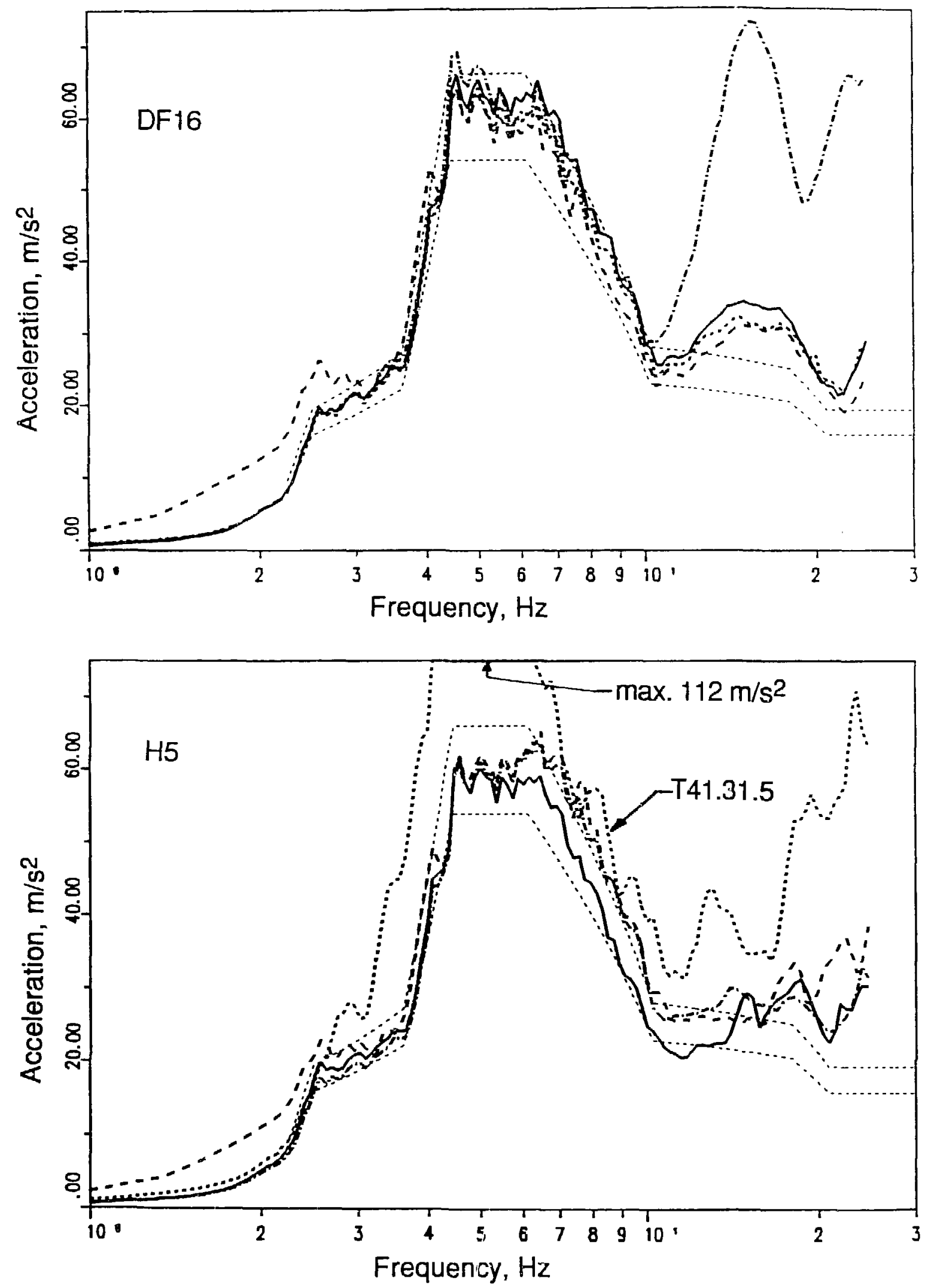

Fig. 6. Input Response Spectra for $300 \%$-SSE Experiments, 4\% Damping 
developed. These difficulties should also be kept in mind when examining the results presented here and when drawing any conclusions.

\subsection{Comparisons at $100 \%$ SSE}

Figures 7 to 10 show peak response values for various variables at 100\%-SSE-input load (HDR common spectrum, $0.6 \mathrm{~g}$ ZPA) for all six support configurations. When making comparisons, it shnild be remembered that the CEGB configuration was designed for a different spectrum, namely, the Sizewell $B$ spectrum which peaks at lower frequency.

The differences in peak accelerations (Fig. 7) in the 200-min pipe and at the valve are not large between configurations, the stiffest NRC configuration giving the lowest values at two location (QB116, QB940). On the 100-mm pipe, the more flexible configurations (HDR and CEGB) give higher responses at the elbow following the reduction tee (QB101) and at midspan (RS761). The situation is reversed at the top of the pipe run close to the DF16 manifold (QB112).

Figure 8 presents the peak forces at the aciuators (H5 and DF16) and at the permanent struts $\mathrm{H} 4$ and $\mathrm{H}_{23}$. Two forces are given for the latter since this support consisted of two parallel struts. It can be seen that these two forces are not equal and that, for strut H23.1, the flexible configurations (HDR, CEGB) result in lower forces :han the other hanger configurations. At actuator $\mathrm{H} 5$, only the most flexible HDR configuration differs signiticantly, whereas at actuator DF16, the peak forces vary from about $32 \mathrm{kN}$ to 42 $\mathrm{kN}$ but no consistent variation with support system stiffiness is apparent. At the other control support $\mathrm{H} 4$, the lowast force corresponds :s the stiffest NRC support system and the most flexible HDR system gives the highest force.

Comparing the maximum bending stresses in the 200-mm piping (Fig. 9), one sees that the NRC configuration gives the highest stresses in the branch emanating from the DF16 manifold (QA100, QA102). On the other hand, in the pipe coming from the HDU (QA104, QA105) and at the valve (QA937), the NRC configuration gives the lowest stresses. In the smaller diameter pipe (Fig. 10), the bending stresses are consistently high for the more flexible configurations (HDR and CEGB), whereas the stiff NRC configuration, in general, exhibits the lowest peak stresses. The stress results are confirmed by the maximum strain measured in the elbows. Elbow 1 in the 200-mm pipe, next to the DF16 manifold, shows the highest strains for the stiff NRC configuration, while Elbow 2, in the 100-mm pipe directly following the reduction tee, yields the highest strains for the flexible configurations (HDR and CEGB).

Other comparisons made include the maximum faces in the rigid struts. In general, the stiff NRC configuration gives lower peak forces than the snubber replacement configurations and the more flexible KWU configuration. In particular, at hanger location $\mathrm{H3}$, the force for the seismic stops exceeds that for the snubbers by more than a factor of two (14.4 vs. $6.6 \mathrm{kN})$. Finally, if forces at snubber locations are compared, one finds that the seismic stops result in the highest forces at four locations $(\mathrm{H} 7, \mathrm{H} 8, \mathrm{H} 12$ and $\mathrm{H} 22$ ). At $\mathrm{H6}$, the peak seismic-stop force is somewhat lower than for the NRC snubber. At location $\mathrm{H} 2$, the seismic stop made no contact with the impact disc spring and no force was recorded.

\subsection{Effect of Increasing Excltation}

Only the KWU support configuration was subjected to the entire range of excitation levels from $100 \%$ to $800 \%$ SSE. While the modified NRC configuration, with the bridging between the DF16 manifold and 200-mm pipe, was also tested in the range from $200 \%$ to $800 \%$ SSE, multiple snubber failures occurred $(\mathrm{H} 8, \mathrm{H} 12, \mathrm{H} 22)$ during the $600 \%$-SSE test. These snubbers were not replaced for the $800 \%$ SSE test. Snubbers $\mathrm{H} 8$ and $\mathrm{H} 12$, which failed so as to permit free motion without resistance, remained installed, while snubber $\mathrm{H} 22$, which lailed with resistance, was removed for the $800 \%-\mathrm{SSE}$ test. During the latter test, snubber $\mathrm{H} 7$ also failed after $6.5 \mathrm{~s}$, when it reached force levels of about $60 \mathrm{kN}$. Finally, the bridging failed in this test, at about $12 \mathrm{~s}$, as did the anchors at location $\mathrm{H} 2$. At lower levels of excitation, snubbers $\mathrm{H} 6$ and $\mathrm{H} 8$ failed in the original unmoditied NRC configuration during the $300 \%-S S E$ 


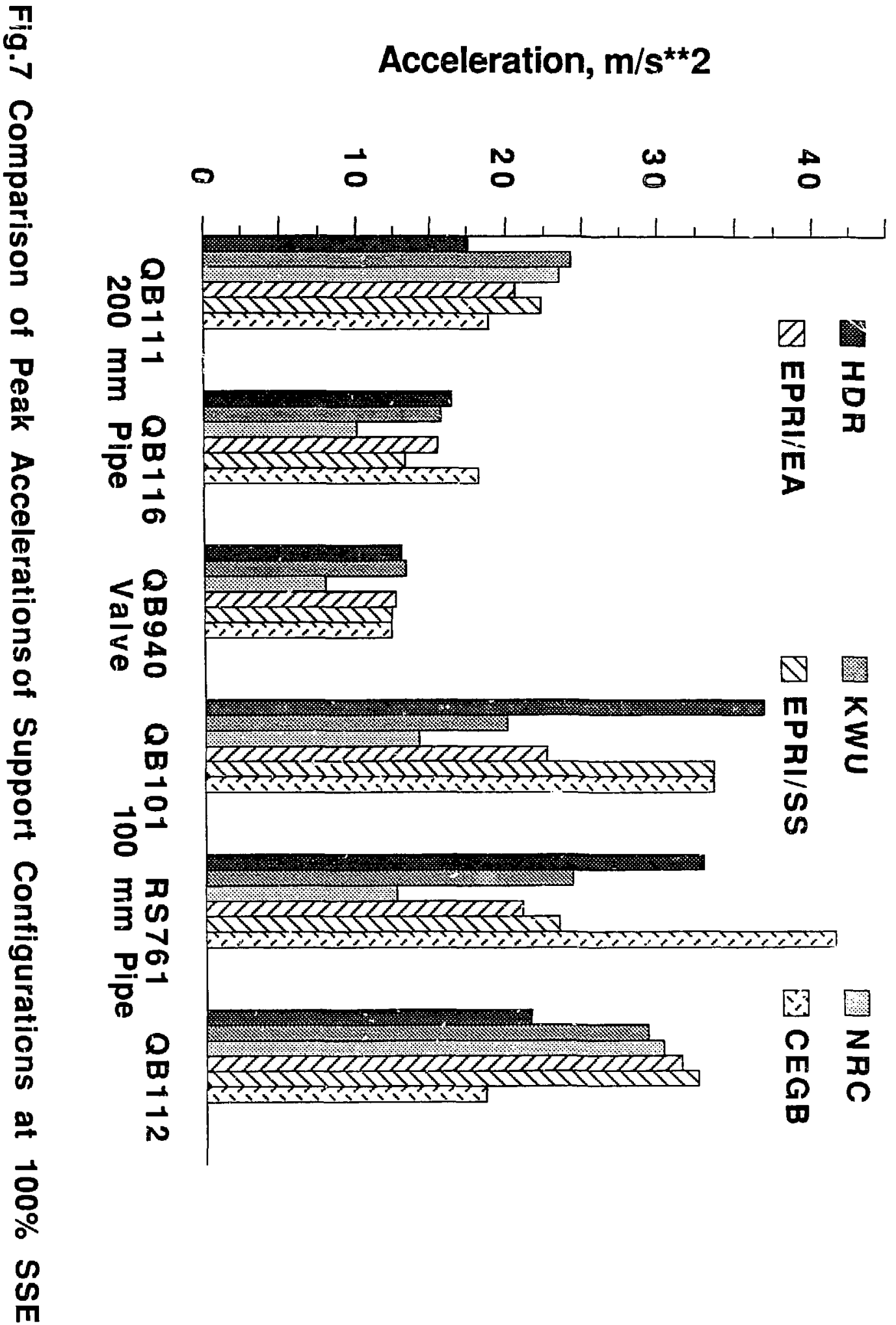




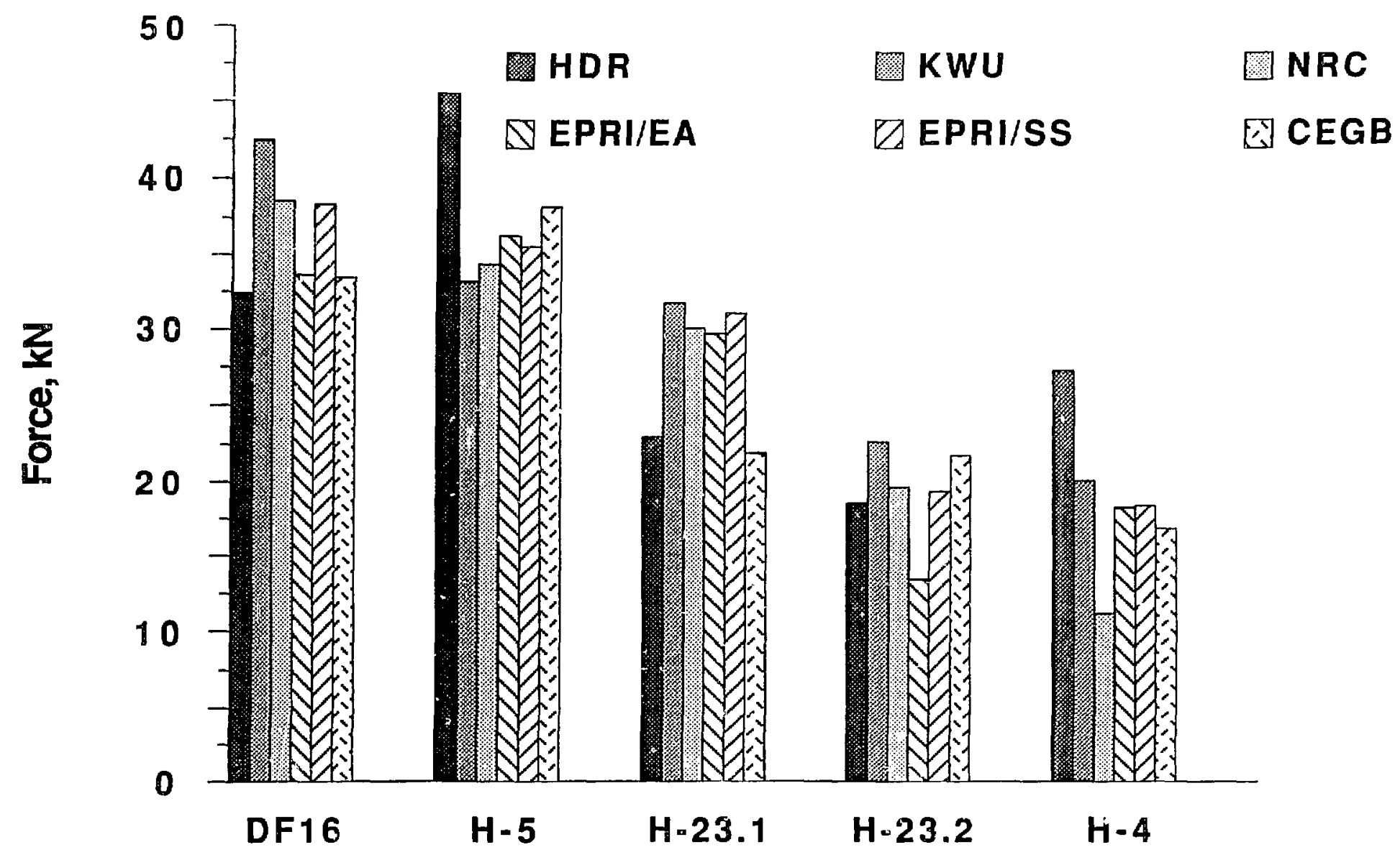

Fig.8 Comparison of Forces in the Common Struts and Actuators of Support Configurations at $100 \%$ SSE 


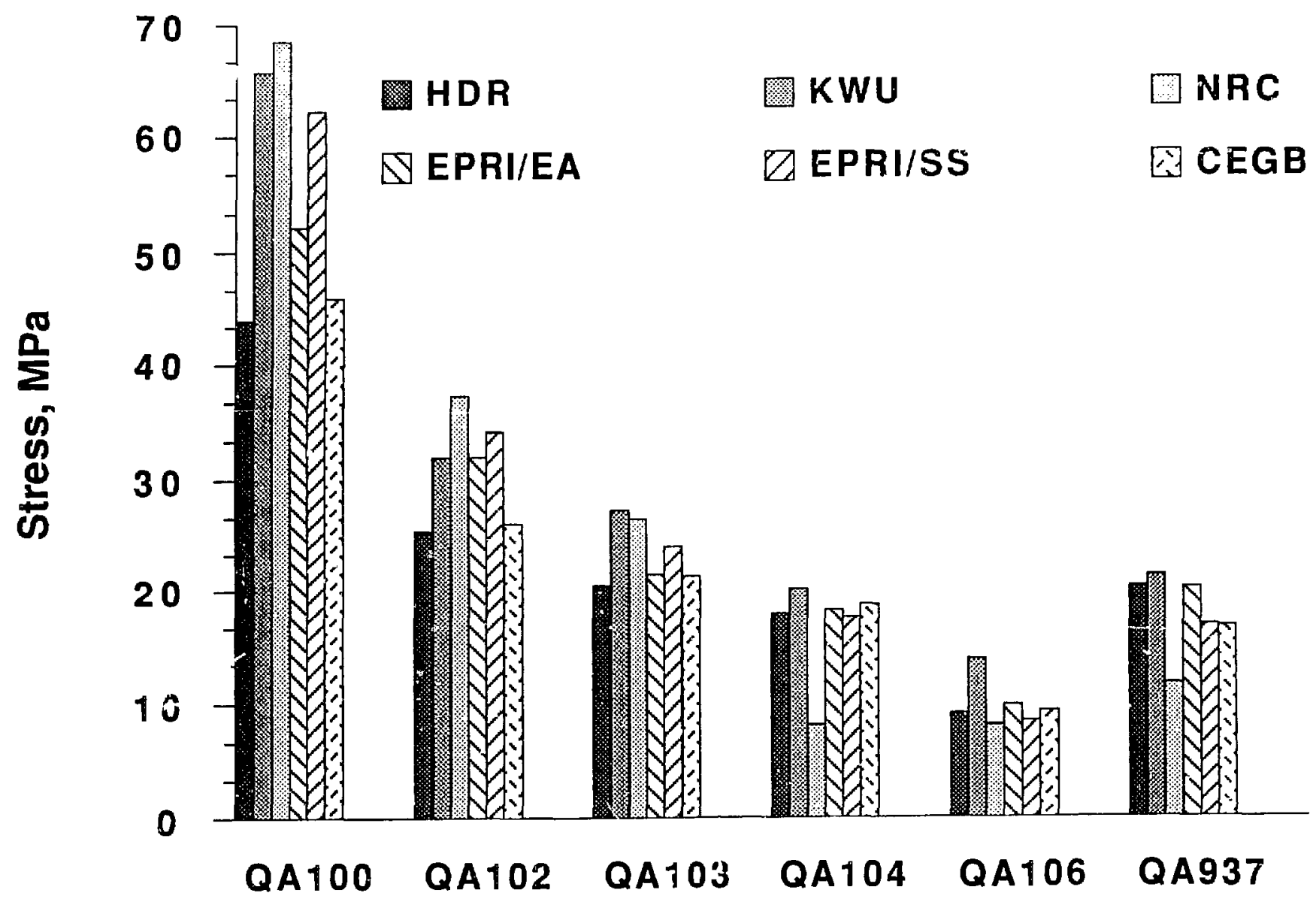

Fig.9 Comparison of Maximum Bending Stress in 200-mm Pipe and Valve of Support Configurations at $100 \%$ SSE 


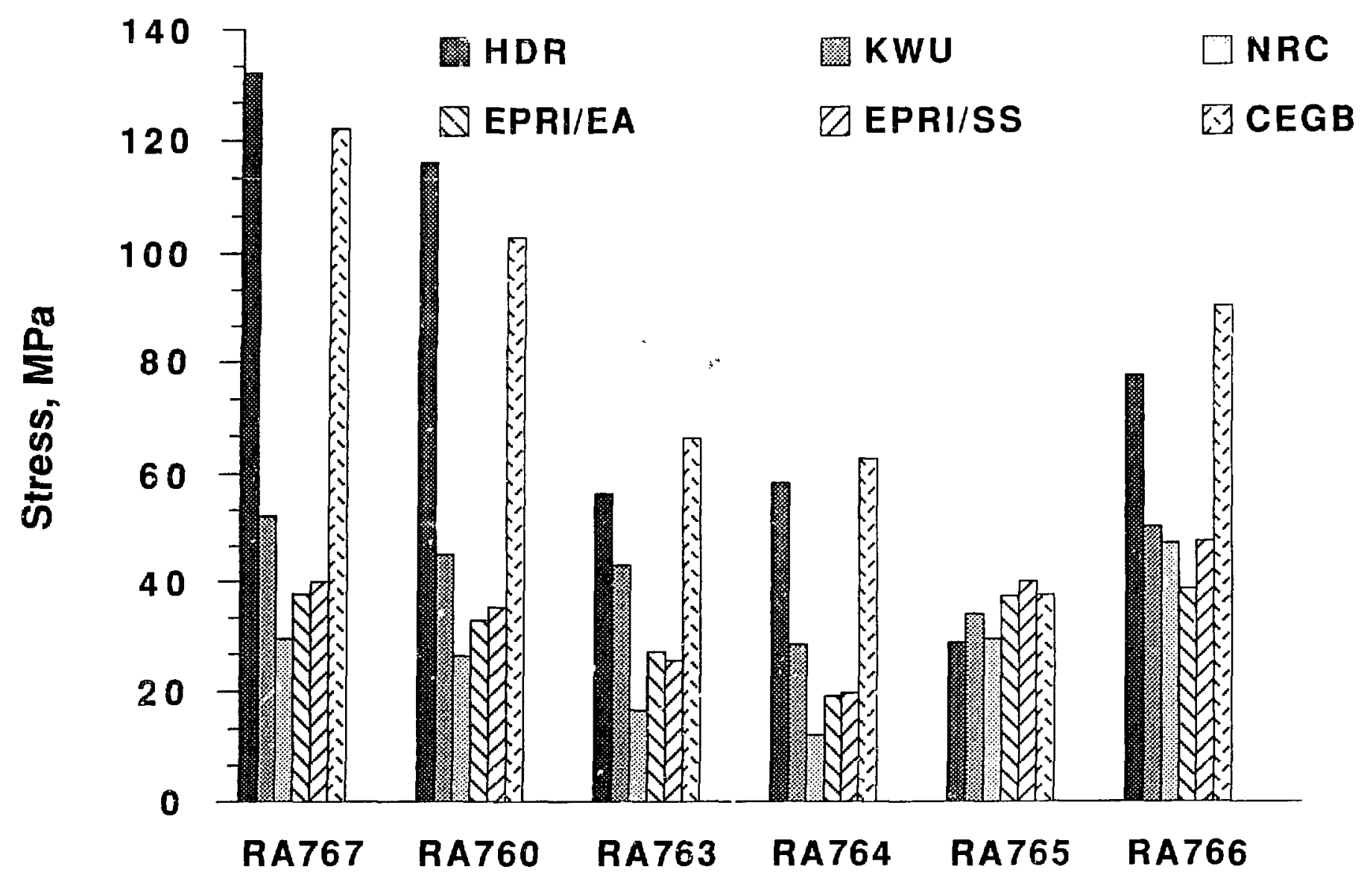

Fig.10 Comparison of Maximum Bending Stress in 100-mm Pipe of Support Configurations at $100 \%$ SSE 
test. The other configurations did not experience support fallures, in particula;, none of the rigid struts failed in any of the tests. Since dynamic support failures may drastically alter the behavior of piping, the above-outlined events should be kept in mind wher comparing the peak responses of the various support configurations.

Figure 11 presents the maximum bending stresses at location QA100, the most highly stressed straight-pipe section in the 200-mm pipe, directly adjacent to Elbow 1, next to the DF16 manifold. At excitation levels up to $300 \%$ SSE, most support configurations gave similar results, with the flexible HDR systemi exhibiting the lowest stresses. Installation of the bridging in the NRC system drastically lowered the response (see $200 \%-S S E$ level). The peak bending stresses for the KWU configuration increase nearly linearly, with the excitation level reaching a maximum of about $380 \mathrm{MPa}$ at a load of $800 \% \mathrm{SSE}$. The stress level corresponding to a $0.2 \%$ offset strain for the pipe material is about $260 \mathrm{MPa}$, as indicated in Fig. 11. Thus, some plastification did occur in both the $600 \%$ and $800 \%$ tests. The plastification level $(0.2 \%$ offset strain! was barely reached by the modified NAC configuration. Also in this case, the maximum bending stress increased faster than linearly with load level. However, this may be due to the aforementioned support failures. A very similar result was obtained for the maximum strains in Elbow 1.

A comparison of the maximum bending stresses at the most highly stressed straight-pipe section of the 100-mm pipe (RA767), shown in Fig. 12, reveals that the litore flexible configurations (HDA and KWU) give the highest stresses at the lower load levels. Both the energy absorbers and seismic stops result in somewhat lower stresses than the snubber configuration. Again, the modification of the NRC system by bridging significantly lowers the bending stress (200\% SSE). The stress increase for the KVVU configuration is nearly linear with excitation level, whereas, for the modified NRC system, the stress increase with load is much steeper than linear. Again, this is probably due to support failure, particularly for the $800 \%$-SSE case when the snubber at $\mathrm{H} 7$ failed and the NRC system nearly became the same support configuration as the KWU system. The peak recorded bending stress of $580 \mathrm{MPa}$ for the KWU configuration exceeds the $0.2 \%$ offset strain level by more than a factor of two. Thus, significant local plastification is to be expected at this section.

Examining the naximum forces in the rigid strut at location $\mathrm{H} 10$ (100 mm pipe) in Fig. 1.3, one can see that the more flexible KWU support configuration gives the highest values at all load levels. Again, the force varies almost linearly with excitation level. The modification of the NAPC coifiguration reduces the strut force somewhat (200\%-SSE case) and again, increases with load at a rate that is steeper than linear.

\section{Pretest Computational Efforts}

As indicated earlier, a number of desigr calculations were performed prior to the SHAM experiments. Linear finite-element analyses were carried out In all cases and simplified modeling of the dynamic supports was used. Thus LBF, using the SAP5 code, performed experiment jesign and actuator performance calculations for the NAC, KWU, IhDR configurations. Using the NUPIPE II code, INEL designed the NRC support configuration and the actuator-stabilizing struts $\mathrm{H} 4$ and $\mathrm{H} 23$. Spectral and time history analyses were performed with typical design procedures for both the two-point excitation and actual earthquake input-loading at all supports. CEGB desigried their support system with the ADLPIPE computer code. They also performed a design computation for the NAC configuration. Similar efforts were carried out by Bechtel and Cloud in the design of the EPRI/EA and EPRI/SS configurations, respectively. In both cases, in-house proprietary computer codes based on SAP and adapted to the specific support configurations were employed. Again, standard design procedures were followed, in which spectral analysis was performed with enveloping and peak-broadened input spectra.

The only true predictive calculations were carried out by ANL for the NRC support configuration. The piping analysis module of the SMACS code [5] was used in the analysis. The pseudostatic-mode approach was used in these calculations; this allowed for time-history analysis with independent support motion input. Again, the basic FE formulation was based on the SAP IV code. In addition, dead weight 


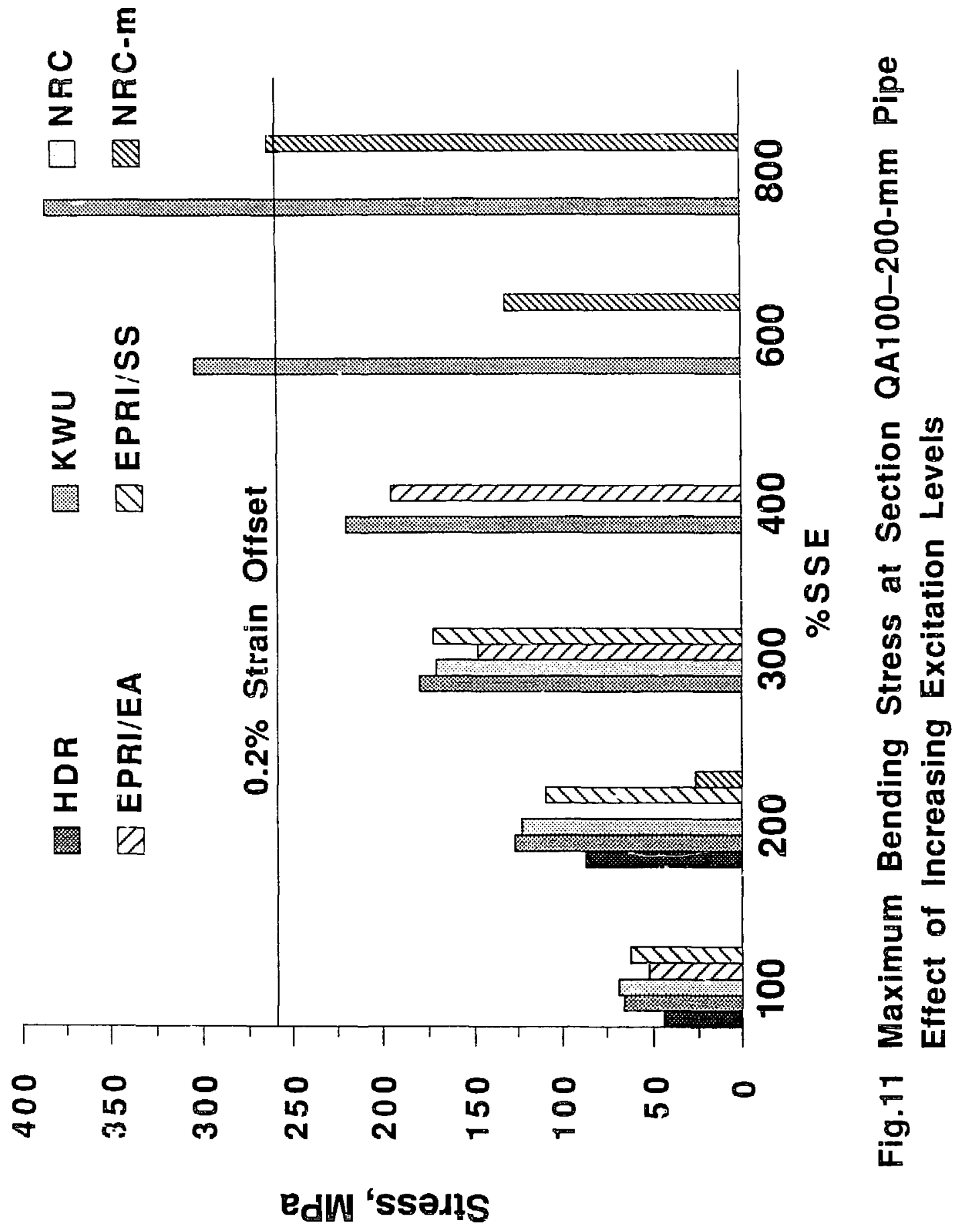




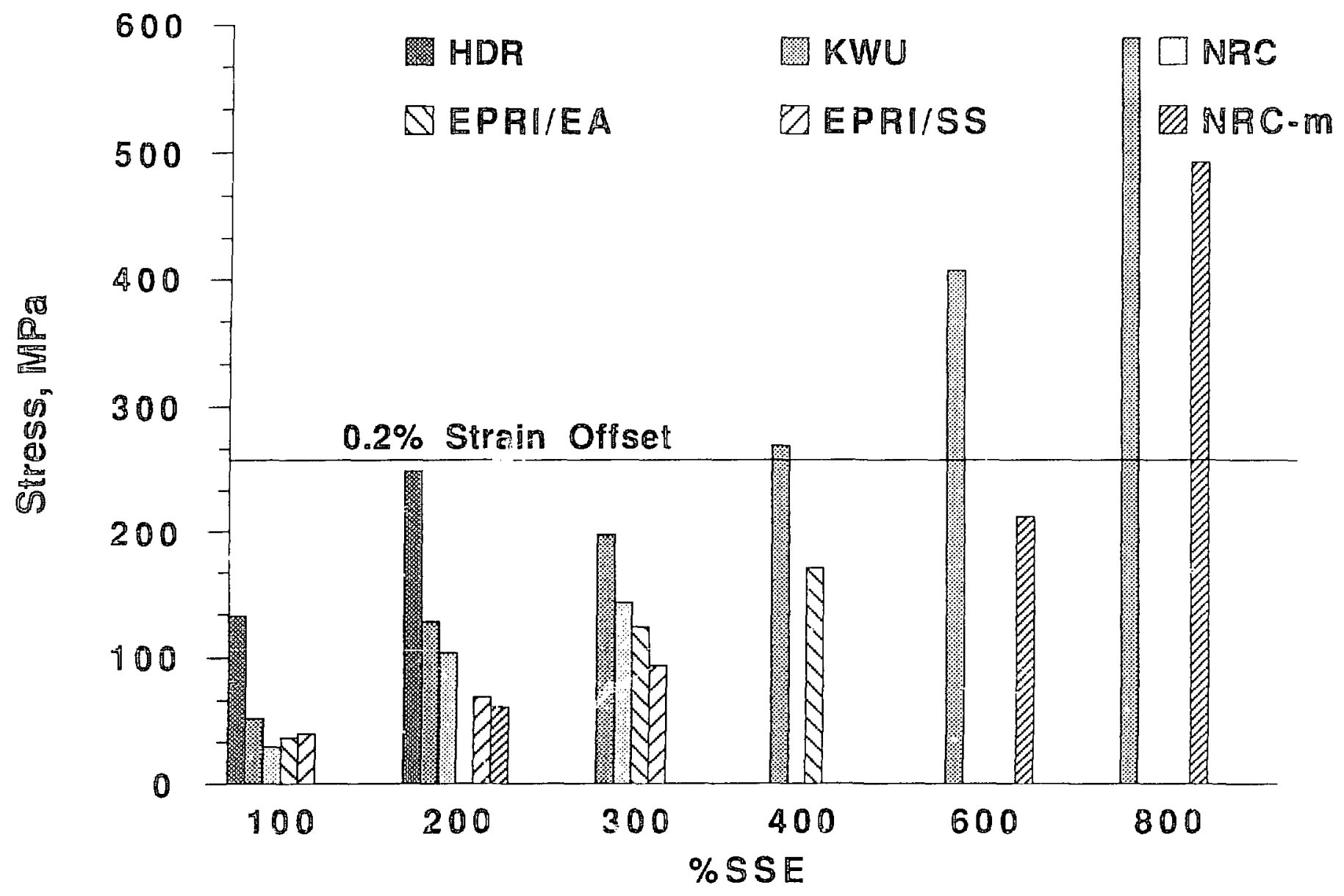

Fig.12 Maximum Bending Stress at Tee, RA767-100-mm Pipe: Effect of Increasing Excitation Levels 

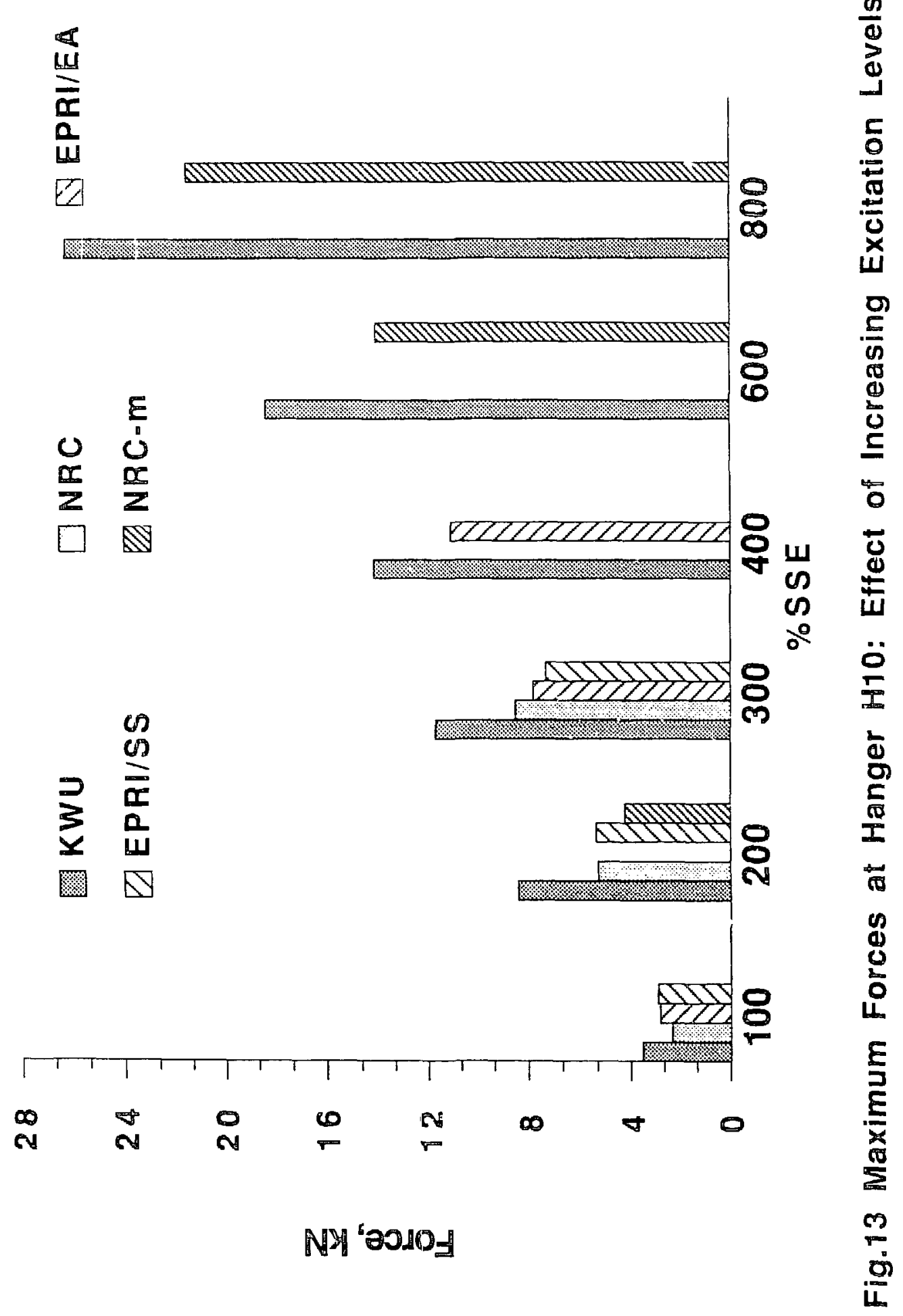
stress and modal analyses were periormed for the NRC system by means of SUPERSAP. The first eigenfrequency was found at about $5.56 \mathrm{~Hz}$.

The peak response values as calculated by the SMACS piping analysis are compared with measured values in Figs. 14-16. The peak forces in the rigid struts of the NRC configuration at excitation levels of $100 \%-300 \%$ SSE are compared in Fig. 14, which shows that all peak forces were underpredicted, often by as much as a factor of two. A similar result was obtairied for the permanent struts $\mathrm{H} 4$ and $\mathrm{H}_{23}$, where the discrepancies are even larger, with the measured value being 3 to 4 times larger than the calculated results.

The measured and calculated maximum snubber forces are compared in Fig. 15 for the excitation range from $100 \%$ to $300 \%$ SSE. Again, the calculation generally predicts substantially lower values than those measured. The exception is the snubber location $\mathrm{H} 2$, where the calculation overestimates the peak forces. The measured peak forces for the $300 \%$ SSE excitation at locations $\mathrm{H} 6$ and $\mathrm{H} 8$, which are designated by arrows, are seen to be lower than the values obtained for the lower excitation levels of $100 \%$ and $200 \%$ SSE. Failure of these snubbers during the $300 \%$ SSE test is the most likely cause for this anomaly. Post-test inspection of the snubbers seems to confirm this supposition. Further analysis of the data is needed to investigate these failures in more detail.

Finaliy, Fig. 16 compares the calculated and measured peak bending stresses in the most highly stressed straight-pipe sections of the 200-mm (QA100) and 100-mm (RA767) pipe. Again, the calculations generally underestimate the stresses. Similar results are found when one examines the stresses at other locations in the pipe. While there are some locations, particularly in the 100-mm pipe. where the predictions overestimate the stresses at the 100\%-SSE level; the situation in general reverses at higher inads, i.e., the calculations underpredict.

An explanation for the underprediction of the peak dynamic support forces can possibly be based on the fact that the analysis is linear and does not account for such nonlinear effects as minor impacts caused by $\subseteq$ z.ps and play in the support hardware. However, the underprediction of the peak bending stresses car , ot be readily explained at this time. The more conservative design calculations, pertormed by other investigators, exhibit some of the same deficiencies as the ANL "best estimate" prediction. Again, peak forces in many supports, and even peak stresses, are underpredicted. Much more detailed data analysis and post-test calculations are required to ascertain the precise causes for the differences between calculation and experiment. At this time, it can only be surmised that a contributing factor to these differences could be the large deviations of the experimental excitations (histories, spectra) from the ideal excitations assumed in the calculations. In particular, the differences in the excitations at DFiE and $\mathrm{H} 5$, observed in the tests, could be of signiricance.

\section{Conclusions}

The results given in the preceding sections are very preliminary and incomplete. Hence, it is not possible to present any final, quantitative and conclusive evaluations of either the support configurations, seismic margins, or pipe behavior. However, based on the total experimental performance of the SHAM test series, the foliowing preliminary qualitative observations can be made:

- It appears that stitf support systems with snubbers and struts, such as the NAC configuration, offer no particular advantages over systems with snubber replacement devices (EPRI/EA and EPRI/SS) or rez sonably compliant systems (KWU).

- Long, unsupported pipe runs may lead to excessive displacements and high stressec under seismic loading, as evidenced by the behavior of the HDR configuration.

- In general, failures of dynamic supports (in particular, snubbers) and of anchorages occur only at load levels that substantially exceed the design capacity. 


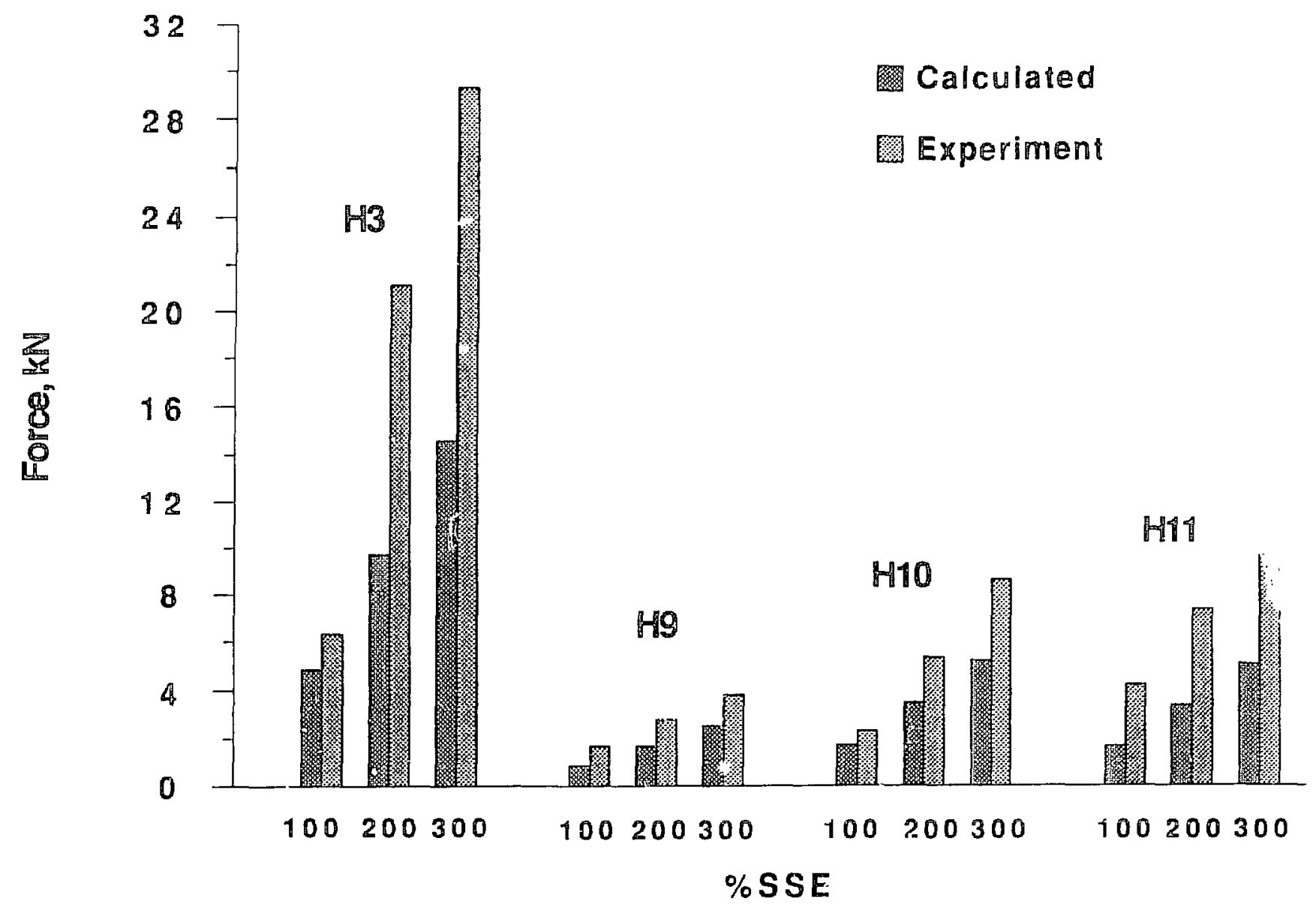

Fig. 14 Calculated and Experimental Maximun Strut Forces: Effect of Excitation Level - NRC Configuration 


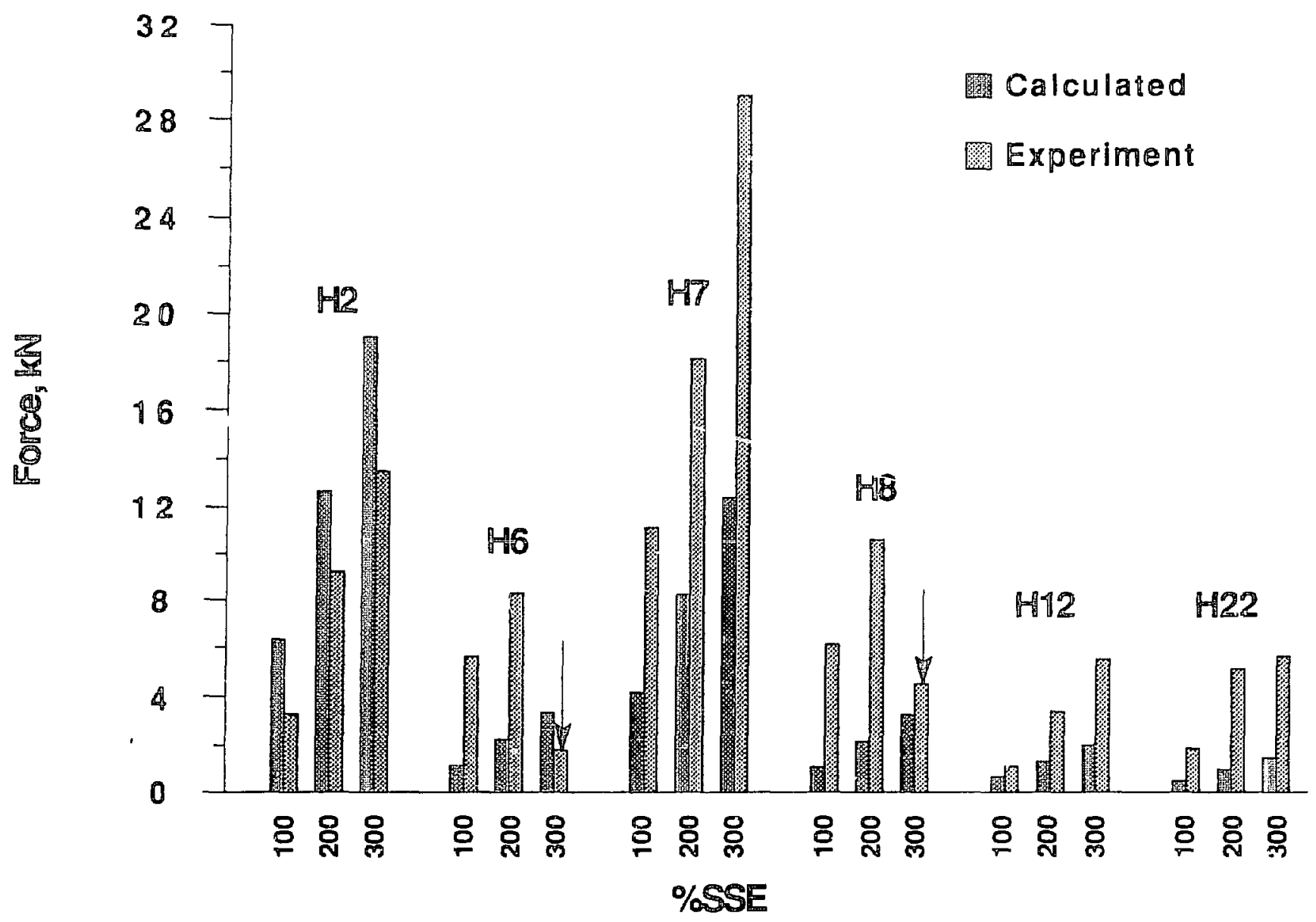

Fig.15 Calculated and Experimental Maximum Snubber Forces: Effect of Excitation Level - NRC Configuration 


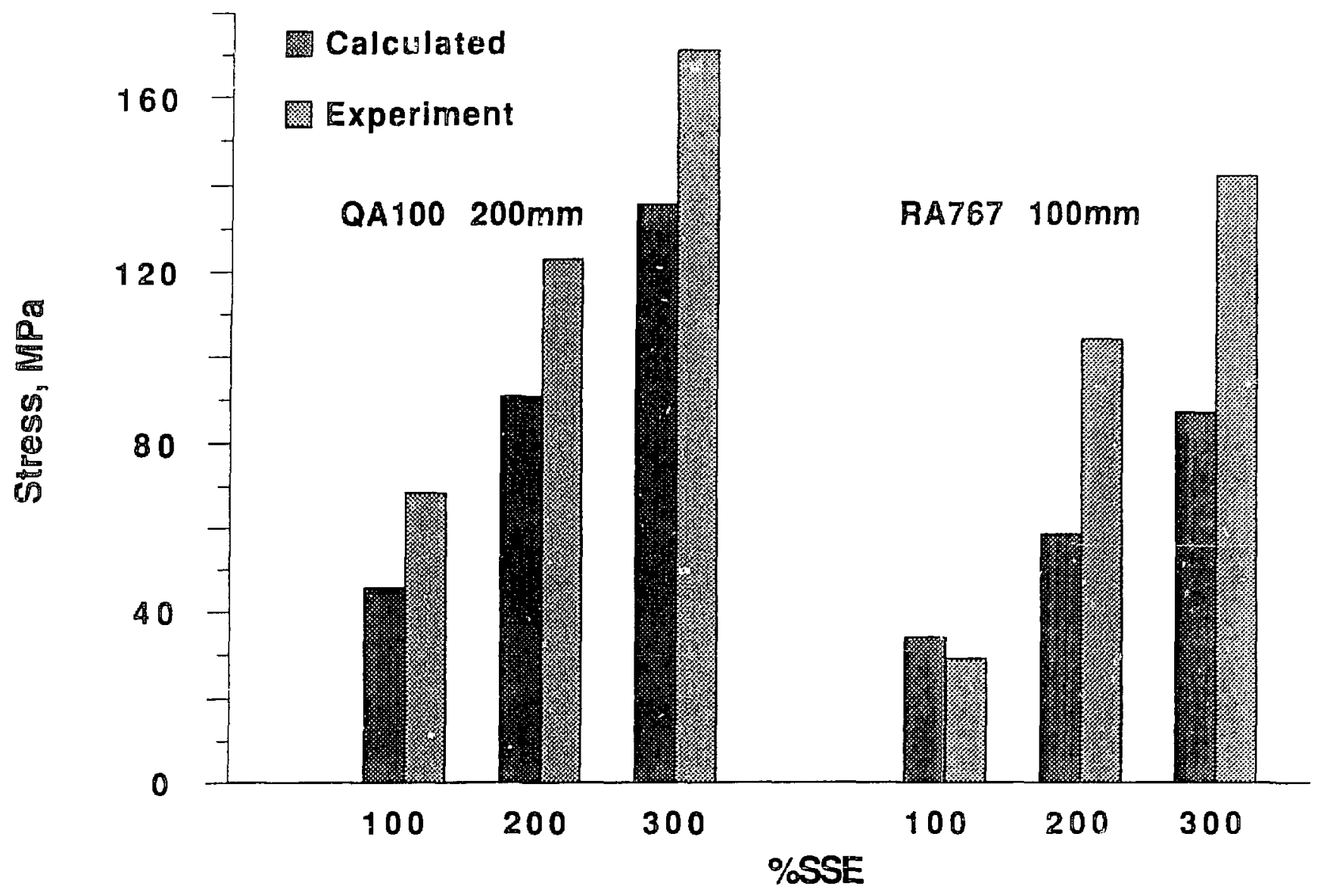

Fig.10 Calculated and Experimental Maximum Bending Stress: Effect of Excitation Level - NRC Configuration 
- $\quad$ Pipe strains and deformations at excitation levels of up to $300 \%$ SSE remain quite small (about $0.3 \%$ ) and even at extreme excitation levels of $800 \%$ SSE are quite tolerab!e (about $1.0 \%$ ). This is true in spite of multiple dynamic support failures.

Pipe failure under typical seismic loading histories, even at extreme load levels (800\% SSE) and in spite of multiple serial support failures, is highly unlikely. It appears that significant strain ratcheting is only feasible by repeated high-load cycling such as may be produced by sine burst loading.

- Linear piping analysis appears to substantially underpredict the peak loads in dynamic supports, and is not necessarily conservative in estimating pipe stresses.

\section{References}

1. L. Malcher and C. A. Kot, "HDR + nase II Vibrational Experiments," Proceedings of the U.S. NRC 14th Water Reactor Safety Inf imation Meeting, NUREG/CP-0082, Vol. 3, pp. 295-312, NBSGaithers:burg, MD, October 27-31, 1986.

2. C. A. Kot, L. Malcher, and H. Steinhilber, "Vibrational Experiments at the HDR: SHAG Results and Planning for SHAM," Proceedings of the U.S. NRC 15th Water Reactor Safety Information Meeting, NUREG/CP-0091, Vol. 3, pp. 251-277, NBS-Gaithers'urg, MD, October 26-29, 1987.

3. L. Malcher, H. Steinhilber, and D. Schrammel, "Design Report -- Servohydraulic Excitation of Mechanical Equipment, HDR Test Group SHAM, vs. No. T41," PHDR Work Report No. 4.338/88, Maich 1988.

4. H. H. Wenzel, L. Löhr, and R. Grimm, "Versuchsprotokoll Servohydraulische Anregung Maschinentechnik, Versuchsgruppe SHAM, Versuch T41," Vol. 1, PHDR-Arbeitsbericht Nr. 4.345/88, Apri? 201988 to May 27, 1988.

5. J. J. Johnson, et al., Seismic Safety Margins Research Program, Phase I Final Report, "SMACS. Seismic Methodology Analysis Chain with Statistics (Project VIII)," NUREG/CR-2015, Vol. 9, UCRL-53021, 1981. 